INGVARSSON, P. K. (2005): Nucleotide polymorphism and linkage disequilibrium within and among natural populations of european aspen (Populus tremula L., Salicaceae). Genetics. 169: 945-953.

Molecular genetics: educational and methodical manual (edited by S. Boronnikova) (2007): Perm State University, Perm (in Russian).

Nyвом, H. (2004): Comparison of different nuclear DNA markers for estimating intraspecific genetic diversity in plants. Molecular Ecology. 13: 1143-1155.

PeAKall, R. and P. E. SMouse (2006): GENALEX 6: genetic analysis in Excel. Population genetic software for teaching and research. Molecular Ecology Notes. 6: 288-295.

Rogers, S. O. and A. J. Bendich (1985): Extraction of DNA from milligram amounts of fresh, herbarium, and mummified plant tissues. Plant Molecular Biology. 5: 69-76.

Salvini, D., M. Anzidei, S. Fineschi, M. E. Malvolti, D. TAURChini and G. G. Vendramin (2001): Low genetic differentiation among Italian populations of Populus tremula L. (Salicaceae) estimated using chloroplast PCR-RFLP and microsatellite markers. Forest Genetics. 8: 81-87.

YeH, F. C., D. K. Chong and R. C. YAng (1995): RAPD variation within and among natural populations of trembling aspen (Populus tremuloides Michx.) from Alberta. Journal of Heredity. 86: 454-460.

WRIGHT, S. (1984): Evolution and the genetics of populations. Genetics and Biometric Foundations. V. 2: Theory of gene frequencies. University of Chicago Press, Chicago.

\title{
Variation and Stability in Female Strobili Production of a First-Generation Clonal Seed Orchard of Chinese Pine (Pinus tabuliformis)
}

\author{
By Huwei Yuan ${ }^{1)}$, Zhexin Li ${ }^{2)}$, Pan FanG ${ }^{3)}$, Wei Li*) and Yue $\mathrm{LI}^{*}{ }^{*}$ \\ National Engineering Laboratory for Forest Tree Breeding, Key Laboratory for Genetics and Breeding of Forest \\ Trees and Ornamental Plants of Ministry of Education, Beijing Forestry University, Beijing 100083, P.R. China
}

(Received $16^{\text {th }}$ June 2013)

\begin{abstract}
Seed orchards of Chinese pine, Pinus tabuliformis, are in a transition period from first generation to advanced generation. During this crucial period, evaluation of seed production in seed orchards is essential. Female strobili production is an important factor in seed production. This study examined the variation and stability in female strobili production in a first-generation clonal seed orchard of Chinese pine in years $9,10,13,14,20$ and 21 after grafting in 1974 . The results showed significant variation in female strobili production among clones, years, and interactions between clones and years. Correlations in female strobili production between years were significant. The repeatability for female strobili production within the examined years ranged from 0.47 to 0.87 . The relative stability of female strobili production varied among clones, with regression coefficients among individual clones and an environmental index ranging from 0.13 to 2.81 . The productivity index in different clones ranged from -1.09 to 1.83 . Yield stability of female strobili among clones could be
\end{abstract}

\footnotetext{
1) E-Mail: yuanhuwei86@163.com.

2) E-Mail: lizhexin_8903@163.com.

3) E-Mail: fangpanysu@yahoo.cn.

*) Corresponding authors: WEI LI and YUE LI. Tel.: +86-10-62336064, Fax: +86-10-62337855. E-Mail: bjfuliwei@bjfu.edu.cn; liyue@bjfu.edu.cn.
}

estimated from female strobili production. Clones could be divided into three groups according to their stability and productivity parameters. The results of this research provide guidance for evaluating clones in existing seed orchards, as well as some basic information for seed orchard management and advanced-generation seed orchard establishment.

Key words: Pinus tabuliformis, first generation, clonal seed orchard, female strobili production, variation, stability, productivity, seed orchard management, advanced-generation seed orchard establishment.

\section{Introduction}

Clonal seed orchards are expected to provide large amounts of seeds of high genetic quality (AsKEw, 1988; MATZIRIS, 1993; BURCZYK and CHALUPKA, 1997; KANG and LINDGREN, 1999). Ideal seed orchards should be composed of clones that meet several conditions, including flowering synchronization, random distribution of clones and ramets, parental balance, and panmictic mating (KANG et al., 2004; KANG and MUlLIN, 2007; PRESCHER et al., 2007; Li et al., 2012). These expected conditions cannot be achieved in real seed orchards owing to clonal variation in flowering (O'REILLY et al., 1982; BYRAM et al., 1986; SCHOEN et al., 1986). Consequently, it is important to study flowering phenology and flower production in seed orchards (ERIKSSON et al., 1973; KANG, 2000; 
KANG and MulLIN, 2007), which are essential factors in achieving maximum seed production (FASHLER and ELKassaby, 1987; ReynoldS and El-Kassaby, 1990; Li et al., 2012). Variation in flowering can cause an accumulation of group co-ancestry and inbreeding (BILIR et al., 2002) and affects genetic diversity and the production of seed crops in seed orchards (NIKKANEN and RUOTSALAINEN, 2000; KANG et al., 2004).

Chinese pine (Pinus tabuliformis Carr.) is a native tree species of high importance in temperate and warm temperate zones, as well as in sub-humid and semiarid regions of China. Attention to this coniferous tree has been increasing because of its irreplaceable status in economic development and environmental protection in northern mountainous regions of China. A genetic improvement program for Chinese pine started in the 1970s (WANG et al., 1985) and great achievements have been made in many aspects, including tree selection, production and quality of seed lots, pollen dispersal, and assessment of the reproductive system (WANG and SHEN, 1989; CHEN et al., 1992; ZHANG and SHEN, 2002; LI et al., 2011; Li et al., 2012). In spite of the achievements obtained so far, seed orchards of Chinese pine are still in a first-generation stage because of a long-term lack of economic and policy support, and seed yields are far from meeting the increasing need for afforestation in vast mountainous areas of northern China. Genetic improvements of Chinese pine will soon be incorporated into first-generation seed orchards and in the establishment of advanced-generation seed orchards. Consequently, there is an essential and urgent need to effectively evaluate clones during this crucial transition period.

Flowering phenology and flower production are important factors in evaluating clones. Flowering phenology has been studied in the Xingcheng seed orchard of Chinese pine (Li et al., 2012). However, theories and methods are not sufficient to provide breeders with sufficient information on variation and stability in flower production in clones in the Xingcheng Chinese pine seed orchard. Female strobili production may have a greater impact than pollen production on seed production in a seed orchard because pollen production is usually sufficient in mating systems.

In this paper, variation and stability in female strobili production in clones were studied in a first-generation seed orchard of Chinese pine. The main goals of this study were to (1) understand variation and stability in female strobili production among clones in this orchard; (2) determine if some clones are superior to others in female strobili production; and (3) provide some basic information about pruning and roguing in first-generation seed orchards and parent selection for establishing future seed orchards.

\section{Materials and Methods}

\section{Studied seed orchard and traits examined}

This investigation was conducted in a first-generation clonal seed orchard of Chinese pine located in Xingcheng City, Liaoning Province, China $\left(40^{\circ} 44^{\prime} \mathrm{N}, 120^{\circ} 34^{\prime} \mathrm{E}\right.$, alti- tude in $100 \mathrm{~m}$ a.s.l.). The orchard had a $7 \times 7 \mathrm{~m}$ fixed block design. Clones in the orchard were transplanted into the field in 1975, after grafting in 1974 using 2year-old rootstocks (SHEN et al., 1985).

Numbers of female strobili were estimated in years 9 , $10,13,14,20$, and 21 after grafting. Four ramets per clone were chosen randomly in 47 clones in the orchard. The number of female strobili was collected by counting all female strobili one by one in each of the selected ramet.

\section{Climatic conditions}

The studied area is in the warm temperate zone and has a typical continental monsoon climate with four distinct seasons. The area is windy in spring, hot in summer, cool in autumn, and cold in winter. Droughts occur occasionally in spring, autumn, and winter, whereas wet conditions occur in summer. Climatic data for the study area were provided by the Meteorological Bureau of Xingcheng City.

The annual average temperature was $8.6^{\circ} \mathrm{C}$. January is the coldest month in a year, with a monthly average temperature of $-9.1{ }^{\circ} \mathrm{C}$. The warmest time of the year is in July, with a monthly average temperature of $24.0^{\circ} \mathrm{C}$. The average annual precipitation in the study area was $543.7 \mathrm{~mm}$. Total precipitation values in spring, summer, autumn, and winter were $76.4,353.6,98.3$, and 14.8 $\mathrm{mm}$, respectively.

\section{Data analysis}

Analysis of variance was carried out based on the observed number of female strobili for each clone. Phenotypic and genetic correlation analyses were adopted to estimate stabilities in female strobili production among the observed years. The Anova model of stability in female strobili production between years was calculated as

$$
Y_{i j k}=\mu+C_{i}+Y_{j}+C Y_{i j}+e_{i j k}
$$

where $Y_{i j k}$ is the observed value of the $k$ th ramet of clone $i$ in the $j$ th year, $\mu$ is the total mean, $C_{i}$ is the effect of the $i$ th clone, $Y_{j}$ is the effect of the $j$ th year, $C Y_{i j}$ is the effect between clones and years, and $e_{i j k}$ is the residual.

Repeatability was estimated as

$$
r=\frac{V g+V e}{V t}
$$

where $r$ is the repeatability, $V_{g}$ is the genotypic variance, $V_{e}$ is the general environment variance and $V_{t}$ is the total phenotypic variance.

Regression analysis was used to evaluate stability in female strobili production among clones, as proposed by EBERHART and RUSSELL (1966).

$$
\begin{aligned}
& \text { Annual environmental index: } I_{j}=\sum_{j}^{n} Y_{i j} / f-\sum_{i}^{f} \sum_{j}^{n} Y_{i j} / n f \\
& \text { Regression coefficient: } b_{i}=\sum_{j}^{n} Y_{i j} I_{j} / \sum_{j}^{n} I_{j}^{2}
\end{aligned}
$$

where $Y_{i j}$ is the observed value of the $i$ th clone in the $j$ th year, $f$ is the number of clones, $n$ is the year, $I_{j}$ is the 
Table 1. - Variation in female strobili production of the years in Xingcheng Chinese pine seed orchard.

\begin{tabular}{ccccccc}
\hline Age & N & Mean & Minimum & Maximum & $\begin{array}{c}\text { Standard } \\
\text { deviation }\end{array}$ & $\begin{array}{c}\text { Coefficient of } \\
\text { variation (\%) }\end{array}$ \\
\hline 9a & 47 & 36.27 & 0.75 & 251.25 & 44.79 & 123.49 \\
$10 \mathrm{a}$ & 47 & 43.63 & 1.75 & 153.92 & 35.19 & 80.66 \\
$13 \mathrm{a}$ & 47 & 171.62 & 7.50 & 397.50 & 83.00 & 48.36 \\
$14 \mathrm{a}$ & 47 & 95.31 & 0 & 298.33 & 66.62 & 69.90 \\
20a & 47 & 516.47 & 147.25 & 796.75 & 231.63 & 44.85 \\
$21 \mathrm{a}$ & 47 & 556.81 & 65.00 & 1539.00 & 342.64 & 61.54 \\
\hline
\end{tabular}

Note: 9 a represents the $9^{\text {th }}$ year after grafting in this seed orchard of Chinese pine. Similar comments also apply to other years. $\mathrm{N}$ represents the number of investigated clones.

annual environmental index, which is defined as an index independent of the experimental varieties and obtained from all environmental factors, $b i$ is the regression coefficient between each clone and the environmental index, and $b_{i}=1$ means that clones have mean stability. If $b_{i}$ is significantly $<1$, then clones are not sensitive to the environment; if $b_{i}$ is significantly $>1$, then clones are sensitive to the environment.

The productivity index (PI) was calculated as

$$
P I=\frac{\dot{g}_{i}}{\sum\left|I_{j}\right| / \mathrm{A}},
$$

where PI represents the seed-producing ability, with a high value implying high productivity, $\mathrm{A}$ is the number of years, $I_{j}$ is the annual environment index, and $\dot{g}_{i}$ is the relative effect on clonal female strobili production. $\dot{g}_{i}$ was calculated as $\dot{g}_{i}=\left(\bar{y}_{i} . .-\bar{y}_{\ldots} ..\right) / \bar{y}_{\ldots}$, where $\bar{y}_{i} .$. is the mean of clone $i$ in all of the observed years, and $\bar{y} \ldots$ is the mean of all clones.

\section{Results}

\section{Variation in female strobili production}

Variation in female strobili production of the years in Xingcheng Chinese pine seed orchard was shown in Table 1. As can be seen, average, minimum and maximum of female strobili were different among the observed years. Average of female strobili production
Table 2. - Analysis of variance in female strobili production in Xingcheng Chinese pine seed orchard.

\begin{tabular}{cccc}
\hline $\begin{array}{c}\text { Sources of } \\
\text { variation }\end{array}$ & $\begin{array}{c}\text { Degrees of } \\
\text { freedom }\end{array}$ & $\begin{array}{c}\text { Mean } \\
\text { squares }\end{array}$ & F-test \\
\hline Years $(\mathrm{Y})$ & 5 & 8565658 & $110^{* *}$ \\
Clones $(\mathrm{C})$ & 46 & 172129 & $2.22^{* *}$ \\
$\mathrm{Y} \times \mathrm{C}$ & 230 & 77557 & $2.59^{* *}$ \\
Residual & 846 & 29897 & \\
\hline
\end{tabular}

*** represent significant at 0.01 level.

increased with increasing orchard year. Coefficient of variation in year 9 and year 10 were higher than that in other years.

Table 2 showed the results of analysis of variance in female strobili production in Chinese pine. The variation in female strobili production was highly significant among clones and years. Additionally, there was a significant effect of the clone by year interaction on variation in female strobili production. Variation in female strobili production could be explained by several factors: different clones have different growth rates relative to female strobili production, which is determined by genetic factors; flowering and fruiting rhythms vary from clone to clone; or changes in environmental factors in different years affected the flowering process to varying degrees.

Table 3. - Correlation analysis of female strobili production among years in Xingcheng Chinese pine seed orchard.

\begin{tabular}{ccccccc}
\hline Age & $9 \mathrm{a}$ & $10 \mathrm{a}$ & $13 \mathrm{a}$ & $14 \mathrm{a}$ & $20 \mathrm{a}$ & $21 \mathrm{a}$ \\
\hline $9 \mathrm{a}$ & 0.47 & $0.43^{* *}$ & $0.38^{* *}$ & $0.50^{* *}$ & $0.81^{* *}$ & $0.70^{* *}$ \\
$10 \mathrm{a}$ & 0.52 & 0.84 & $0.67^{* *}$ & $0.60^{* *}$ & $0.61^{* *}$ & $0.50^{* *}$ \\
$13 \mathrm{a}$ & 0.61 & 0.81 & 0.87 & $0.72^{* *}$ & 0.40 & $0.50^{* *}$ \\
$14 \mathrm{a}$ & 0.89 & 0.77 & 0.77 & 0.81 & 0.44 & $0.54^{* *}$ \\
$20 \mathrm{a}$ & 0.99 & 0.87 & 0.55 & 0.66 & 0.83 & $0.76^{* *}$ \\
$21 \mathrm{a}$ & 0.99 & 0.48 & 0.57 & 0.67 & 0.99 & 0.68 \\
\hline
\end{tabular}

Note: 9a represents correlation coefficient in the $9^{\text {th }}$ year after grafting in this seed orchard of Chinese pine. Similar comments also apply to other years. Data on the diagonal represent repeatability $(\mathrm{R})$; data above the diagonal represent phenotypic correlation coefficients; data below the diagonal represent genetic correlation coefficients.

*** represent significant at the 0.01 level. 
Correlation in female strobili production among and within years

As shown in Table 3, the correlation analysis for female strobili production among years revealed that phenotypic correlations between most of the years observed were significant. Correlation coefficients appeared to fluctuate randomly between the years investigated, which might be explained by cyclical changes in female strobili production and different flowering rhythms among clones. The genetic correlation coefficients between years ranged from 0.48 to 0.99 and were higher than the phenotypic correlation coefficients (ranging from 0.38 to 0.81 ), demonstrating that female strobili production between years was under strong genetic control and was inherited reliably in most of the examined clones. Repeatability for female strobili pro- duction within the years investigated ranged from 0.47 to 0.87 (Table 3), with an average of 0.75 , which demonstrates that the total genetic effects on female strobili production were above moderate. The differences in repeatability reflected changes in female strobili production from the early flowering stage to the stable flowering stage. Repeatability in year 9 (0.47) was lower than in the other years examined, possibly because there was large variation among ramets within clones in female strobili production in the young seed orchard, and this variation decreased and became stable with increasing orchard age.

\section{Stability in female strobili production among clones}

Given the highly significant variation that was observed in the interaction between clones and years

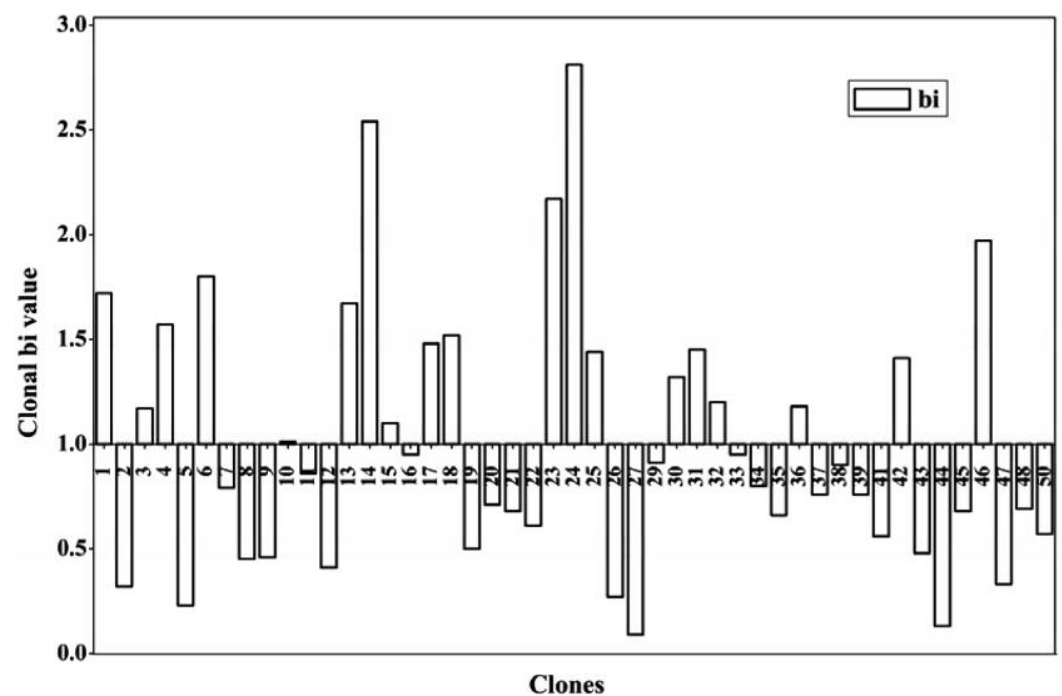

Figure 1. - Stability in female strobili production in different clones in the Xingcheng Chinese pine seed orchard.

Note: the bar represents the regression coefficient between a certain clone and the environmental index (bi).

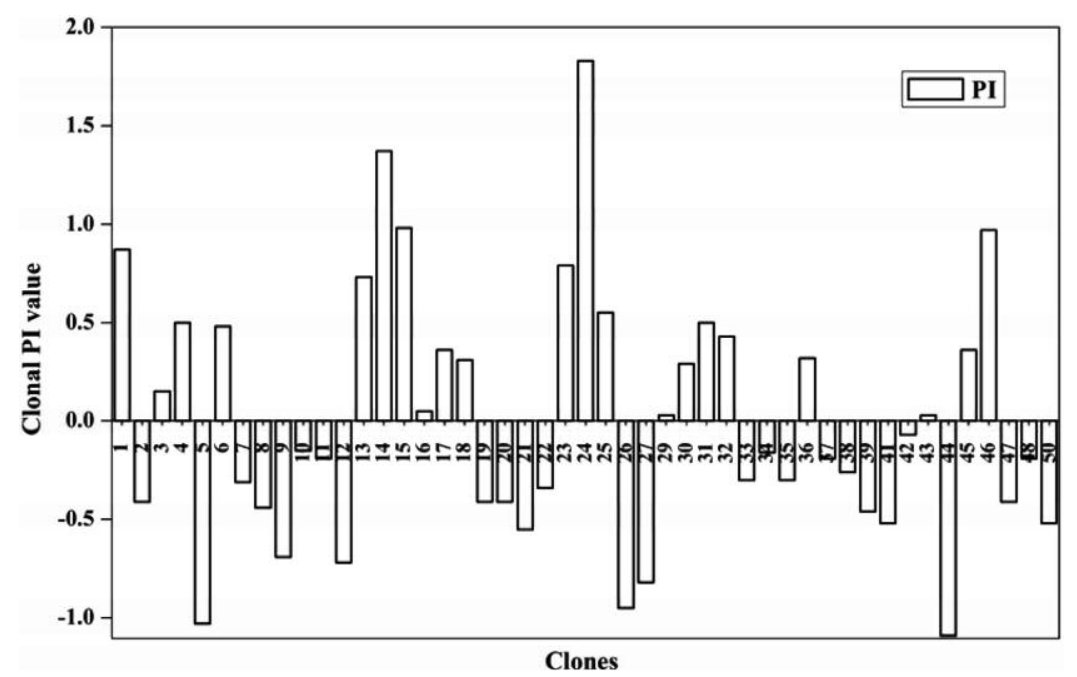

Figure 2. - Productivity index values for female strobili production in different clones in the Xingcheng Chinese pine seed orchard.

Note: the bar represents the productivity index (PI) value of a certain clone. 


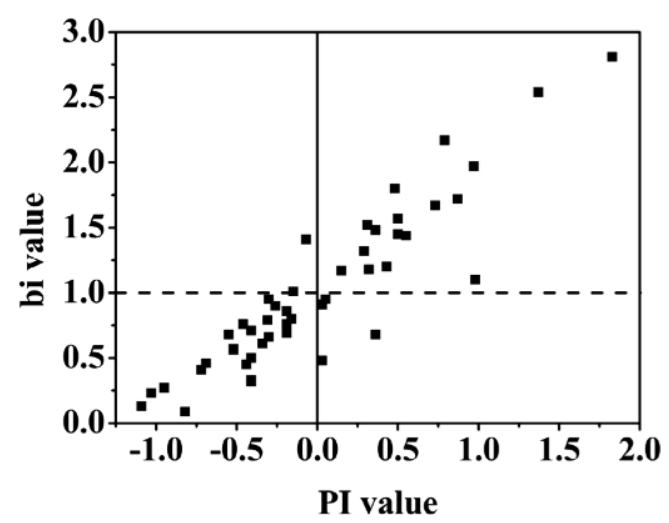

Figure 3. - Classification of clones in the Xingcheng Chinese pine seed orchard.

Note: bi represents the regression coefficient between a certain clone and the environmental index; PI represents the productivity index value of a certain clone.

relative to female strobili production (Table 2), an additional study was conducted to understand the differences in yield stability among clones in different years. The results showed significant differences in the relative stability of female strobili production among clones when environmental conditions changed (Figure 1). Twelve clones in the orchard $(25.53 \%)$ exhibited mean stability $\left(b_{i} \approx 1\right)$, meaning that female strobili production in these clones was relatively stable throughout the investigated years. A total of $21(44.68 \%)$ clones had a $b i$ value significantly less than 1 , indicating that female strobili production in these clones was not sensitive to changes in environmental factors among years. The remaining 14 clones, whose $b_{i}$ values were significantly higher than 1 , had low stability in female strobili production among years.

\section{Productivity index values for female strobili production in different clones}

Productivity index (PI) values for female strobili production in different clones were presented in Figure 2. In the studied clones, the productivity index values in the different clones ranged from -1.09 to 1.83 . Clone 14 and clone 24 had the highest PI values. Clones with relatively high productivity index values included clones $15,46,1,23$, and 13. Twenty one clones had PI values larger than 0 and 26 had PI values smaller than 0 . Therefore, the productivity index for female strobili production varied from clone to clone.

\section{Evaluation and classification of clones}

Clones in the orchard were evaluated based on the stability and productivity index information (Figures 1, $2)$. As the figures show, $b i$ and PI indicated the same changing trend. The majority of clones with high PI values had large $b i$ values, which meant that yield stability in most high-PI-value clones was extremely low. Similarly, yield stability in most low-PI-value clones was extremely high, indicating that female strobili production was not sensitive to environmental changes among years. Clones with moderate PI values had mean stability in female strobili production. Consequently, yield stability in female strobili production can be initially esti- mated from female strobili production. The clones in this Chinese pine seed orchard could be divided into three groups according to their production and yield stability in female strobili production (Figure 3). Clones in group 1 had high female strobili production, but production was not stable. Clones in group 3 showed an opposite pattern from that in group 1 . Female strobili production was moderate in group 2 , but production was stable among the observed years.

\section{Discussions}

Seed orchards are built to provide seeds that have high yield and genetic value. Seed production in a seed orchard cannot be maximized if production fluctuates due to changes in environmental factors among years, differences in seed-producing ability among different clones, and interactions between clones and environmental factors, which will ultimately affect genetic constitution, genetic diversity, and afforestation in the progeny. In a seed orchard, annual changes in environmental factors are objective. Studies should concentrate on the clones themselves and interactions between clones and environmental factors.

Female strobili production is an important factor that is highly related to seed production in seed orchards. Studies of variation in female strobili production form the basis of seed orchard management in first-generation seed orchards and aid clone selection for advancedgeneration orchards. Variation in female strobili production has been observed in many coniferous species. The significant variations among clones and years in female strobili production that were observed in this paper agreed with previous reports for Chinese pine (LI et al., 1996), Scots pine (BurCZYK and ChalupKa, 1997; SivaCIOGLU et al., 2009), Korean pine (KANG and LindGREN, 1998; KANG and LINDGREN, 1999), and Pinus thunbergii (KANG et al., 2004). The interaction between clones and years relative to female strobili production was significant during the study period in this seed orchard, which was in accordance with previous reports (KANG et al., 2004; ERIKSSON et al., 1973).Variations in the interaction between clones and sites were found for both cone and seed traits in another study (TODHUnTER and PoLK, 1981).

The phenotype of a certain trait is controlled by the genotype and the environment. The influence of the environment on a phenotype cannot be ignored when interactions between the genotype and environment are significant. In this case, there were strong interactions between environmental factors and the genotypes that should be considered in stability analyses. The yield stability analysis for female strobili production showed that, in this orchard, 35 clones that accounted for $71.4 \%$ of the production had $b_{i}$ values close to or below 1 , as was found in another Chinese pine seed orchard (LI et al., 1996). Variation in yield stability in female strobili production provides a foundation for robust clone selection and orchard evaluations.

High strobili production has always been considered an important factor for seed production in nearly all seed orchards of coniferous species (KANG and LINDGREN, 
1999; NiKkANEN and RUOTSALAINEN, 2000; KANG et al., 2004). The imbalance in female strobili production among clones in this Chinese pine seed orchard demonstrated that clones contribute unequally to seed crops in real seed orchards. A few superior clones could contribute a large proportion of the total seed production. Similar results have been observed in several coniferous tree species (O'REILLY et al., 1982; SCHOEN et al., 1986; BYRAM et al., 1986; KANG et al., 2004). Parental imbalance could cause a decline in diversity in the seed crop and would ultimately affect genetic diversity in the progeny.

Seed orchards of Chinese pine are in a transition period from first generation to advanced generation. Advanced-generation seed orchards usually have fewer clones than first-generation orchards, and thus it is very important to evaluate and select clones effectively. Ideal elite clones must have the genetic potential for superior performance under ideal growing conditions, and must also produce acceptable yields under less favourable environments. Therefore, a stable genotype can be considered to be one that is capable of using the resources that are available in high-yielding environments and that has a mean performance that is above average in all environments. Clones found to have low female strobili production should be eliminated first, in agreement with the conclusions of another study (KANG and LINDGREN, 1998). Attention should focus on clones that have moderate female strobili production when establishing advanced-generation seed orchards. The elimination or retention of clones with high female strobili production should depend on the specific situation. Some clones with high female strobili production could be chosen as elite clones because the number of years in which these clones are best suited to the environmental conditions is larger and some clones (such as clone 15 in this orchard) have stable flower production. Clones that could not boost productivity should be treated as candidates for elimination in this Chinese pine seed orchard. The combination of selecting for both stability and productivity could aid in comprehensive and systematic evaluations of clones in existing seed orchards.

\section{Conclusions}

Several conclusions can be drawn from this research: variation in female strobili production was highly significant among clones and years, and was affected by the interaction between clones and years in the Xingcheng first-generation Chinese pine seed orchard. Year-year correlations in female strobili production in the Xingcheng Chinese pine seed orchard were under strong genetic control. The relative stability of female strobili production varied from clone to clone in the years studied in the Xingcheng Chinese pine seed orchard. Yield stability in female strobili production among clones could be estimated from female strobili production. Yield stability in high-yield clones was extremely low. Female strobili production in low-yield clones was not sensitive to changes in environmental factors. Clones with moderate female strobili production showed mean yield stability among years.

\section{Acknowledgement}

This work was supported by grants from The Special Fund for Forestry Scientific Research in the Public Interest (No.201104022), The National Natural Science Foundation of China (No. 31370657) and The State Forestry Bureau 948 Project (No. 2012-4-40). We thank the anonymous reviewers for their constructive comments in improving the manuscript.

\section{References}

Askew, G. R. (1988): Estimation of gamete pool compositions in clonal seed orchards. Silvae Genetica 37(5-6): 227-232.

BILIR, N., K. S. KANG and H. OzTURK (2002): Fertility variation and gene diversity in clonal seed orchards of Pinus brutia, Pinus nigra and Pinus sylvestris in Turkey. Silvae Genetica 51(2-3): 112-115.

BuRCZYK, J. and W. CHALUPKA (1997): Flowering and cone production variability and its effect on parental balance in a Scots pine clonal seed orchard. Annals of Forest Science 54: 129-144.

Byram, T. D, W. J. Lowe and J. A. MCGRIFF (1986): Clonal and annual variation in cone production in loblolly pine seed orchards. Forest Science 32(4): 1067-1073.

Chen, B. W., Y. Zheng and X. H. Shen (1992): Studies on Selection Methods and Criteria of Plus Trees in Pinus tabulaeformis Carr. Journal of Beijing Forestry University 14(1): 7-13.

EBERHART, S. A. and W. A. Russell (1966): Stability parameters for comparing varieties. Crop Science 6(1): 36-40.

ERIKSson, G., A. Jonsson and D. LindGREN (1973): Flowering in a clone trail of Picea abies-Karst. Studia Forestalia Suecica 110: $1-45$.

FASHLER, A. M. K. and Y. A. EL-KASSABY (1987): The effect of water spray cooling treatment on reproductive phenology in a Douglas-fir seed orchard. Silvae Genetica 36(5-6): 245-249.

GRIFFIN, A. R. (1982): Clonal variation in radiate pine seed orchards. I. Some flowering, cone and seed production traits. Australian forest research 12: 295-302.

Jonsson, A., J. EkDERG and G. ERIKSson (1976): Flowering in a seed orchard of Pirzus sylvestris L. Studia Forestalia Suecica 135: 1-38.

KANG, K. S. and D. LINDGREN (1998): Fertility Variation and its Effect on the Relatedness of Seeds in Pinus densiflora, Pinus thunbergii and Pinus koraiensis Clonal Seed Orchards. Silvae Genetica 47(4): 196-201.

KANG, K. S. and D. LindGREN (1999): Fertility variation among clones of Korean pine (Pinus koraiensis S. et Z.) and its implications on seed orchard management. Forest Genetics 6(3): 191-200.

KANG, K. S. (2000): Clonal and annual variation of flower production and composition of gamete gene pool in a clonal seed orchard of Pinus densiflora. Canadian Journal of Forest Research 30: 1275-1280.

KANG, K. S., D. LindGren and T. J. Mullin (2004): Fertility variation, genetic relatedness, and their impacts on gene diversity of seeds from a seed orchard of Pinus thunbergii. Silvae Genetica 53(5-6): 202-206.

KANG, K. S. and T. J. MulLiN (2007): Variation in clone fertility and its effect on the gene diversity of seeds from a seed orchard of Chamaecyparis obtusa in Korea. Silvae Genetica 56(3-4): 134-137.

Li, G. F., H. X. Zhang, Y. F. He, H. J. HAN and L. J. JiA (1996): Clonal variation in conelet yield and evaluation 